\title{
Impact of "Formulate, Share, Listen and Create" Strategy On Mathematical Representation Skills
}

\author{
Ibrahim Moh'd Arman
}

\begin{abstract}
The study aimed at investigating the effect of employing the strategy "Formulate- Share- Listen- Create" FSLC on the $4^{\text {th }}$ Graders developing their mathematical representation skills in Governmental Schools in Hebron Governorate - Directorate of Education. In order to achieve the objectives of the study, it was applied on a purposive sample of (124) $4^{\text {th }}$ Graders in Al-Huda Basic Education for Girls School and Al-Amin Basic Education for Boys School in the Directorate of Education / Yatta. The sample included 67 male Students, and 57 female students. The students distributed into four sections, one section in each school represented the Control Group (studied in the Control Method), and the other section represented the Experimental Group (studied according to the Formulate-Share-Listen and Create Strategy FSLC. The researcher built a test of mathematical representation skills, the researcher verified the validity and reliability of the tool. The results revealed that there were statistically significant differences at the level of significance $(\alpha \leq 0.05)$ among the $4^{\text {th }}$ Graders in the test of mathematical representation skills due to the Teaching Method and for the Experimental Group studied according to the strategy FSLC. The study revealed that there were no statistically significant differences at the level of significance $(\alpha \leq 0.05)$ in the test of mathematical representation skills due to Gender, or in the interaction between Gender and the Method. In the light of the results of the study, the researcher recommends training teachers to use the Strategy in developing mathematical written skills (writing and presentation) and the verbal skills (speaking, listening and reading), as well as conducting further studies on the impact of this strategy in other variables and subjects. Such as solving life problems and making decision.
\end{abstract}

Index Terms-FSLC Strategy; Mathematical Representation.

\section{INTRODUCTION}

The field of education in Palestine is undergoing a change movement that included the development of educational curricula, evaluation tools for the lower basic stage and the development of teaching methods and strategies to deal with the large amount of knowledge contained in the curricula, especially mathematics curricula developed in the light of the international standards of mathematics curricula, Active student.

The role of effective mathematics in developing students' mental and life skills, developing the ability to confront scientific problems and finding appropriate solutions, and the need to understand multiple types of knowledge can't be overlooked. However, students' learning of mathematics faces a problem of poor achievement of mathematical

Published on January 27, 2019.

I. M. Arman is with the Department of Education Sciences, Al-Quds University, Abu-Deis, Jerusalem, Palestine. (e-mail iarman@staff.alquds.edu) knowledge and inability to deal with mathematics as cumulative knowledge structures, which is used in all life situations.

It is therefore important to prepare the learner to be able to learn mathematics, and to retain the knowledge that qualifies him to deal with multiple situations both inside and outside the school, and this requires a strong preparation in mathematics.

References [10], [12] and [7]; explored It is necessary to search On modern teaching strategies that help students develop concepts, and active learning strategies are among the best strategies to improve mathematics education and learning, based on structural theory that assumes that the learner builds his or her own knowledge.

The FSLC is an "active learning strategy that requires students to think, read, compose, write, share with colleagues, listen analytically to other participants, and then provide an innovative and different answer to other answers or solutions" [9].

In order for mathematics to become more relevant and more systematic, the concept of mathematical representation emerged as one of the global standards for mathematics education, which appeared in the National Conciliator of the Mathematics [8], which refers to the student's ability to represent concepts, in many ways while preserving the basic picture of the mathematical concept.

Mathematical representation is one of the main objectives of the mathematics curriculum. Mathematics teaching and learning aims to represent situations mathematically and use mathematical language to express them [6].

Reference [1] pointed out that mathematical representation makes the concepts, concepts and relationships more clear and solid, and helps the student to understand the components of knowledge more comprehensively and in depth by identifying the common mathematical elements of the different situations of concepts, in addition to helping to focus on the basic characteristics of the mathematical concept, Mathematical representations work to connect the components of knowledge in such a way as to enable the student to deepen understanding of mathematical concepts and relationships and to use them to solve life problems.

Despite the importance of mathematical representations, studies conducted on mathematics students in Palestine revealed that students suffer from inability in mathematical representation [5].

Reference [3] observation that some students are unable to understand the basic rules of mathematical representation, and therefore it is difficult for them to understand and solve mathematical problems.

Students face problems in mathematical representation. 
They are unable to understand the mathematical concept or mathematical problem and then represent it mathematically. Mathematical knowledge also includes other verbal information, drawings, or symbols.

Therefore, the researcher is interested in experimenting with the FSLC strategy of cooperation, sharing and active learning. This is confirmed by many literatures on the importance of the FSLC strategy in the development of different thinking skills, including the study of [10].

This study was conducted to investigate the impact of the use of the strategy FSLC in the development of mathematical representation skills among $4^{\text {th }}$ Graders.

\section{A. Statement of the Problem}

The researcher noticed a decline in the $4^{\text {th }}$ Graders students in their ability to translate mathematical concepts or express them in other pictures, or to read other representations and express them verbally, and this in turn affected their abilities in learning mathematics and solving mathematical problems in particular.

Accordingly, the problem of the study is determined by the low level of mathematical representation skills among the $4^{\text {th }}$ grade students, which led the researcher to experiment with the use of the FSLC strategy and its impact on mathematical representation.

\section{B. Questions of the Study}

The study aimed to answer the following Question: What is the impact of employing the FSLC strategy in developing the skills of mathematical representation among $4^{\text {th }}$ Graders students? Does this effect differ according to the method (FSLC, Control) and gender, and the interaction between them?

\section{Hypotheses of the study}

The researcher converted the study Question into a Null Hypothesis: There were no statistically significant differences at the level of statistical significance $(\alpha \leq 0.05)$ between the mathematical averages for the development of skills of mathematical representation among the fourth grade students in mathematics due to the method (FSLC, Control), gender and interaction between them.

\section{Objectives of the study}

The study aimed to investigate the effect of the FSLC strategy on the development of the skills of mathematical representation among the $4^{\text {th }}$ Grade students in the public schools of the Directorate of Education / Yatta and whether there is an effect of gender variables and the way and interaction between them.

\section{E. Significance of the Study}

The importance of the study is that it deals with a new orientation of educational trends interested in active learning strategies. The study aims at experimenting with an active learning strategy FSLC in teaching mathematics to $4^{\text {th }}$ grade students and measuring their impact in developing their mathematical skills.

\section{F. Terminology of study}

Strategy FSLC is defined as an active learning strategy that requires students to think, read, compose, write and share to their peers, listen analytically to other participants from the rest of the students, and provide an innovative and different answer to other answers or solutions [9].

The researcher defines it as an active learning strategy that requires working collaboratively among the students. It is based on the active participation of the students, starting with the formation of ideas about mathematical concepts, sharing with colleagues, listening to the opinions and opinions of colleagues and presenting innovative and different answers and ideas.

Mathematical representation: It means the ability to translate a mathematical issue or idea into a new format, and to translate an image represented in an illustration into mathematical symbols and words. Such as representation of numbers in different forms (abacus, cubes, beams, money), translation of the various images of numbers into numeral symbols, translation of verbs into illustrations, illustrations, tables or equations, or translation of picture issues into symbols and mathematical words.

The researcher defines it the expression of mathematical ideas or concepts through the use of multiple tools such as words, tables, drawings or tangible materials.

\section{G. Theoretical Framework and Previous Studies}

FSLC strategy: It is an active learning strategy based on collaborative learning. The activity begins by asking the teacher a question or set of questions about the learning tasks to be learned. The student then thinks individually to answer the questions and then shares with his or her partner. His colleagues in the discussion on individual answers, and then listen with his classmates to discuss the class, then the student proposes some new solutions based on what was done in the previous steps. It is a form of collaborative learning in small groups, and was formulated by developing a strategy of "Think -Share-Create " [11].

The FSLC strategy is one of group-based active learning strategies that includes three steps: individual thinking in the teacher's questions, mating students to think about the problem, and then sharing the suggested answers to the questions with the group, [4].

\section{1) FSLC Steps}

formulate activities, to plan a response plan, to engage students in their responses, exchange views with partners, to answer each other, point out differences and similarities in ideas and opinions, and create students through discussion and dialogue new answers, [10].

The FSLC strategy derives its name from the four steps implemented by the learner during the learning position. These four steps indicate the name of the strategy: Formulate: In which the student answers the questions asked.

Share: The student shares his or her answer with his or her partner His collection.

Listen: In which the student listens to his colleagues and teacher, and learns the similarities and differences.

Create: In which the student presents different answers to the answers raised (to a certain extent).

\section{2) Mathematical Representation}

The international standards of mathematics required that students be able to represent concepts, ideas and mathematical relationships in a variety of ways to facilitate 
the understanding of mathematical knowledge and the ability to re-employ them in multiple learning situations and life situations.

\section{H. Previous studies}

The study [12] revealed the impact of the FormulateShare-Listen-Create strategy in teaching mathematics for Grade $11^{\text {th }}$. The study sample consisted of 40 students from the $11^{\text {th }}$ grade in Nigeria. The tool consisted of a mathematics test. The results showed that the average number of students in mathematics was high and that the students' responses to the implementation of the strategy were positive and high (91.5\%).

Reference [7] also conducted a study aimed at revealing the effectiveness of Formulate-Share-Create strategy in acquiring scientific concepts and promoting the motivation of eighth graders towards science. The study followed the experimental method with experimental and control groups. The study sample consisted of 40 students from the eighth grade. The tools of the study were a test and a measure of motivation. The results of the study showed that the students of the experimental group surpassed the control in testing and motivation. The study recommended applying the mentioned strategy in teaching science.

The study of [2] aimed at uncovering the effectiveness of the F.S.C strategy to develop the visual thinking and mathematical communication skills of the eighth grade students in Gaza. The study followed the experimental method of experimental and control groups. The study sample consisted of 54 students of the eighth grade in the school "Dar al-Arqam special secondary for boys", and the study tools were the test of visual thinking skills and sports communication. The results of the study showed that there were statistically significant differences between the experimental and control groups in the post-application of visual reasoning and mathematical communication for the benefit of the experimental group in both tests. The study recommended using the Think-Share-Create strategy in teaching mathematics.

\section{METHOD AND PROCEDURES}

\section{A. Study Methodology:}

The pilot approach was used to investigate the effect of employing the FSLC strategy in developing the skills of mathematical representation among the $4^{\text {th }}$ grade students.

\section{B. Study Population}

The study population consists of all students of the fourth grade primary school in the Ministry of Education at the Directorate of Education / Yatta, for the academic year 2017/2018, the number of (2522) students.

\section{The study sample}

The researcher chose school (Al-Huda Basic for Girls, AlAmin Basic for Boys) in the Directorate of Education / Yatta, each containing two sections of the $4^{\text {th }}$ Grade Students, and is taught by the same teacher, in order to apply the study in the second semester of the year The experimental subjects were taught according to the FSLC strategy, while the control subjects were taught the same educational material in the Control way.

\section{Validity of the Tool}

The researcher did the validity of the tool of the study by presenting it to a group of experienced and competent.

\section{E. Reliability of the Tool}

The researcher determined the coefficient of stability using the Test-Retest method by applying to a survey sample from the study community and from outside its sample by calculating Pearson correlation coefficient. And it was found to be 0.79 , which is a good stability coefficient and educationally acceptable.

\section{F. Study variables:}

This study was designed to investigate the impact of the use of the FSLC strategy in the development of mathematical representation skills among fourth graders

\section{1) Independent Variable}

Method of teaching according to the FSLC Strategy for Experimental Group Students and the Control Teaching Method for students of the control group.

Gender has two levels (Male and Female)

\section{2) Dependent Variable}

\section{Mathematical Representation Skills.}

\section{3) Statistical Processing}

The Statistical Package for Social Sciences (SPSS) was used to find the Reliability, means, standard deviations, the ANCOVA and the calculation of the ETA Square.

The debug key was used: $2 \leq 0.06$ weak, $0.06 \leq \uparrow 2 \leq 0.14$ medium, $2 \geq 0.14$ large [11].

\section{CONCLUSION}

For answering the Question: What is the impact of employing the FSLC strategy in developing the skills of mathematical representation among 4th Graders students? Does this effect differ according to the method (FSLC, Control), Gender, and the Interaction between them?

The following Null Hypothesis was investigated: There were no statistically significant differences at the level of statistical significance $(\alpha \leq 0.05)$ in the mathematical averages for the development of mathematical representation skills among the fourth grade students in mathematics due to the method of teaching (FSLC, Control), gender and interaction between them.

The arithmetic means and standard deviations were extracted in the test of mathematical representation skills by gender and teaching method as shown in Table II and Table II.

TABLE I: NUMBERS, ARITHMETIC MEANS AND STANDARD DEVIATIONS FOR PRE-TEST AND POST-TEST FOR MATHEMATICAL REPRESENTATION SKILLS DUE TO GENDER VARIABLE

\begin{tabular}{|c|c|c|c|}
\hline \multicolumn{2}{|c|}{ Variable (Gender) } & Pre-Test & Post-Test \\
\hline \multirow{3}{*}{ Male } & Means & 7.22 & 14.93 \\
\hline & Standard Deviation & 4.67 & 7.11 \\
\hline & Number & 67 & 67 \\
\hline \multirow{3}{*}{ Female } & Means & 7.84 & 15.16 \\
\hline & Standard Deviation & 4.10 & 6.37 \\
\hline & Number & 57 & 57 \\
\hline
\end{tabular}


TABLE II: NUMBERS, ARITHMETICAL MEANS AND STANDARD DEVIATIONS FOR PRE-TEST AND POST-TEST FOR MATHEMATICAL REPRESENTATION SKILLS DUE TO THE METHOD VARIABLE

\begin{tabular}{llcc}
\hline \hline Variable (Method) & & Pre-Test & Post-Test \\
\hline \multirow{4}{*}{ Experimental } & Means & 6.89 & 11.76 \\
& Standard & 4.62 & 6.32 \\
& $\begin{array}{l}\text { Deviation } \\
\text { Number }\end{array}$ & 62 & 62 \\
\hline \multirow{3}{*}{ Control } & Means & 8.13 & 18.31 \\
& Standard & 4.14 & 5.50 \\
& Deviation & & 57 \\
\hline \hline
\end{tabular}

Table I and Table II showed that there are apparent differences in the mathematical means of the students' scores in the math skills test.

To find out whether the apparent differences in the mean scores of the students' grades were statistically significant at the statistical significance level $(\alpha \leq 0.05)$, the researcher used the ANCOVA test, and Table III showed that.

TABLE III: ANCOVA ANALYSIS FOR MATHEMATICAL REPRESENTATION SKILLS BY METHOD AND GENDER AND THEIR INTERACTION

\begin{tabular}{lllllll}
\hline \hline Source & $\begin{array}{l}\text { Sum of } \\
\text { Squares }\end{array}$ & $\mathrm{d}_{\mathrm{f}}$ & $\begin{array}{l}\text { Mean } \\
\text { Square }\end{array}$ & $\mathrm{F}$ & Sig & $\begin{array}{l}\text { Eta } \\
\text { Squa } \\
\text { re }\end{array}$ \\
\hline Pretest & 3054.39 & 1 & 3054.4 & $\begin{array}{l}298 . \\
4\end{array}$ & 0.001 & 0.71 \\
Method & 806.53 & 1 & 806.53 & 78.7 & 0.001 & 0.39 \\
Gender & 4.73 & 1 & 4.73 & 0.46 & 0.498 & .004 \\
Method*Gende & 11.93 & 1 & 11.93 & 1.16 & 0.282 & 0.01 \\
r & 1218.26 & 119 & 10.23 & & & \\
Error & 33630.0 & 124 & & & & \\
Total & & & & & &
\end{tabular}

\section{A. Results related to the Method}

It is clear from Table III that the value of the significance level is (0.001), which is less than the statistical significance level $(\alpha \leq 0.05)$. Thus, there are statistically significant differences at the level of statistical significance $(\alpha \leq 0.05)$ between the two experimental groups Which has been studied in FSLC Strategy, and control (taught in the Control way) in post-test of mathematical representation to enhance the teaching method.

To find out the source of the differences, the Estimated Marginal Means were found as showed in Table IV

\begin{tabular}{|c|c|c|}
\hline Method & $\begin{array}{l}\text { Estimated Marginal } \\
\text { Means }\end{array}$ & $\begin{array}{l}\text { Standard Deviation } \\
\text { Error }\end{array}$ \\
\hline Experimental & 17.604 & 0.410 \\
\hline Control & 12.439 & 0.409 \\
\hline
\end{tabular}

It is clear from Table IV that the Estimated Marginal Means of the experimental group (the "co-share-listencreated" FSLC strategy) was 17.604, which is greater than the Estimated Marginal Means the control group studied in the Control method (12.439). The Differences between the two groups in favor of the upper mean, the experimental group studied using the FSLC.

The results also show that the effect of the teaching method was 0.398 , which is higher than the upper limit of the impact by reference point (0.04) in [11], and therefore the effect of the FSLC strategy on the development of mathematical representation skills among the experimental group is large.

\section{B. Results related to the Gender}

It is clear from Table III that the value of the significance level is 0.498 , which is greater than the statistical significance level $(\alpha \leq 0.05)$. Therefore, there are no statistically significant differences at the mean level $(\alpha \leq 0.05)$ between Male and Female Table V illustrate that.

TABLE V: Estimated MARGINAL MEANS FOR GENDER VARIABLE

\begin{tabular}{lcc}
\hline \hline Gender & $\begin{array}{l}\text { Estimated Marginal } \\
\text { Means }\end{array}$ & Standard Deviation Error \\
\hline Male & 15.21 & 0.39 \\
Female & 14.82 & 0.42 \\
\hline \hline
\end{tabular}

Table V showed that the Estimated Marginal Means for Male was (15.21) and Female (14.82).

The results also indicate that the effect of the student gender is 0.004 , which is less than the minimum effect size $(0.04)$ in [11].

\section{Results for interaction between Gender and Method of teaching:}

Table III showed that the value of the significance is 0.282 , which is greater than the statistical significance level $(\alpha \leq 0.05)$. Therefore, there are no statistically significant differences at the level of statistical significance $(\alpha \leq 0.05)$ due the interaction between Method and Gender.

\section{DISCUSSIONS}

The results of the study revealed that there were statistically significant differences at the level of $(\alpha \leq 0.05)$ between the mean of the experimental and control groups in the post-test of the mathematical representation test due to the teaching method in favor of the upper medium.

FSLC $(17,604)$ is greater than the mean of the control group studied in the Control way (12.439). The results revealed a significant effect of the teaching method in the development of mathematical representation in the experimental group.

The researcher attributed the superiority of the students of the experimental group, which was studied according to the strategy of FSLC to the students of the control group studied in the Control way in mathematical representation that the strategy (FSLC allowed students through the four steps to form multiple ideas and different ways (Verbal - symbolic forms) and participation in front of students, and the debate around them, which in turn increased the ability to represent concepts and mathematical ideas.

The researcher believes that the unit of decimals and decimal numbers has many mathematical representations, and taught them through the FSLC strategy to help students understand the content in a wider and deeper way, thus the experimental group surpassed the control group.

Using the FSLC strategy, the strategy gave students the opportunity to be open minded and to look outside the box, which increased students' ability to represent mathematical concepts and ideas in a variety of ways.

As well as participating in the FSLC strategy, the students received feedback on the concepts and mathematical ideas presented, thus benefiting them in the generation and production of multiple mathematical representations, which led to a high degree of mathematical representation among 
students.

The strategy also increased the students 'tendency towards multiple mathematical representations. The researcher noted this through the students' responses to the worksheets and in the mathematics book, and helped the students to better understand the mathematical representation of concepts and mathematical ideas.

This in turn has reflected positively on the understanding of the concepts and generalizations included in the unit of decimals and decimal numbers, and the ability to represent them in more than one way. The result also shows that the FSLC strategy worked in both males and females in the experimental group through its four steps, Re-represent what they have learned in mathematics.

This result can also be explained by the similarity of the circumstances in which the FSLC strategy is applied in terms of following the two parameters for the same educational procedures, using the same teacher guide prepared according to the FSLC strategy, using the strategy sheets in the lesson, Work, and convergence in previous experiences of students because they belong to the same level and the educational environment, as well as provide the same materials, tools and stimuli used for both genderes.

\section{STUDY RECOMMENDATIONS:}

In light of the results of the study, the researcher recommends the following:

1) Include active learning strategies, especially the FSLC strategy in mathematics teacher preparation programs and basic stage teacher.

2) Encourage teachers to use modern teaching strategies that engage students in positive classroom interaction such as FSLC.

\section{REFERENCES}

[1] Abu-Hilal, M. "The Effect of Using Mathematical Representations on Acquiring Concepts and the Orientation towards Mathematics among Sixth Grade Students", Unpublished Master Thesis, Islamic University, Palestine, 2012

[2] Al-Deeb, N. "Effectiveness of the use of a strategy (F.S.C) on developing the skills of visual thinking and mathematical communication among the eighth grade students in Gaza", Unpublished Master Thesis, Gaza, Palestine, 2015.

[3] Al-Harbi, M. "The Relationship between Multiple Mathematical Representations and Solving Verbal Problems in Sixth Grade Students", Unpublished Master Thesis, Umm Al-Qura University, Saudi Arabia, 2014.

[4] Allan, N. "The Effect of F.S.C Strategy on the Achievement of Fourth Year Students in Mathematics and in Developing Their Thinking in the Public Schools in Bethlehem Governorate", Unpublished Master Thesis, Al-Quds University, Palestine, 2013.

[5] Al-Sir, K. The degree of availability of mathematical communication patterns included in mathematics books seventh, eighth and ninth grades in the State of Palestine. Al-Aqsa University Journal (Human Sciences Series), Vol. 19, p. 2, pp. 222-267, Palestine, 2015.

[6] Darabee, H. "The Effect of the Application of Mathematical Representations in Understanding Basic Mathematical Concepts among Eighth Grade Students at Al-Aroub Primary School for Boys,
Hebron", Unpublished Master Thesis, Al-Quds University, Palestine (2017).

[7] Kumar, R., \& Kumar, A Effectiveness of think- pair- share technique over conventional technique in promoting science education at upper primary standard. International Education and Research Journal, 2 (11): 89- 90, 2016.

[8] National Council of teachers of Mathematics (NCTM). Principles and Standards for School mathematics. Reston, VA: NCTM, 2000.

[9] Ramadan H. Strategic Effectiveness FSLC in the development of higher thinking skills and scientific concepts in the science of students in the fifth grade of primary, the Egyptian Association for Scientific Education, Journal of Scientific Education, 11 (3), Egypt, 2008.

[10] Rosyana, T.; Afrilianto, M.; Senjayawati, E. The Strategy of Formulate-Share-Listen-Create To Improve Vocational High School Students' Mathematical Problem Posing Ability and Mathematical Disposition on Probability Concept. Journal of Mathematics Education, V.7, No. 1, 1-6, 2018.

[11] Safi, S. Analysis of linear regression and contrast using SPSS Lectures for Faculty Members, Faculty of Education, Islamic University, 22-24 January 2018, Palestine, 2018.

[12] Yuliana, R.; Setianingsih, R. Implementation of Realistic Mathematics Education with Formulate Share listen Create FSLC Strategy on the Material of Permutation and Combination at Grade Xi SMA Negeri 4 Sidoarjo. Journal Ilmiah Pendidikan Matematika, Volume 3, 2017, Nigeria.

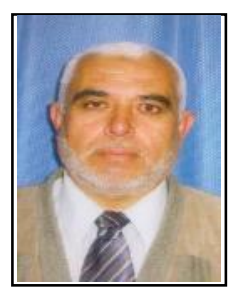

Ibrahim Moh'd Arman, Halhul-Palestine, 10th, Sep. 1960

Instructional Technology, $\mathrm{PhD}$, Ain Shams University, Egypt 2004

Teaching Methods, MA, Al-Quds University, Palestine 1998

Computer Science, B.Sc, Jordan University, Jordan 1983

\section{LECTURER}

Ibrahim Moh'd Arman, Department of Education Sciences, Al-Quds University, Abu-Deis, Jerusalem, Palestine

1-Arman, Ibrahim (2013). Effectiveness of Information Communication Technology Approach on Mathematics Achievement for 8th Grades Students. International Journal of Artificial Intelligence and Mechatronics. Volume 2, issue 3, pp86-90.

2-Hashem, kamel, Arman, Ibrahim (2012). Promoting Mthematical Understanding Using ICT in Teaching and Learning. World Academy of Science, Engineering and Technology. Vol. (71), pp 1401-1404.

3- Hashem, kamel, Arman, Ibrahim (2013). Integration of ICT in Mathematical Understanding Using Modeling. International Journal of Computer and Information Technology Vol 02 Issue 02 March 2013.

4-Naser, Inas; Naffi', Jmal; Arman, Ibrahim (2016). The Degree of Faculty's Use and Stimulation of Students' Critical Thinking from the Perspective of English Majors at Al-Quds University. Journal of Education and Practice. Vol. 7 No 29 (2016), pp35-44.

5-Arman Ibrahim; Naser Inas; Nfi' Jamal (2017).Students Difficulties in Written Expression in The Departments of English and Arabic at Al-Quds University. European Journal of Education Studies. Vol. 3 Issue 1.

6- Arman, Ibrahim (2017). The Impact of Educational Technology on the Acheivement in The General Science Subjects of The 6th Grade Students. International Journal of Research \& Dvelopment Organization. Vol 2 Issue 5, May 2017.

7- Arman, Ibrahim (2017). The Degree of The Employment of Interactive Smart Board in Education by Secondary School Teachers. Journal of Multidisciplinary Engineering Science and Technology. Vol 4, Issue 4, April (2017).

8- Naser, Inas; Arman, Ibrahim; Nfi', Jamal (2017). The Degree of Faculty's Use of Authentic Assessment Tools at Al-Quds University and Their Relation to Their Attitudes Towards Them. International Journal of Education, Learning and Development. Vol 5, No. 7, pp44-63, August 2017.

9- Arman, Ibrahim (2017). The Effectiveness of Using Conceptual Maps Strategy to Treat the Weakness of the Acquisition of the Scientific Concepts for the Students in North Hebron Directorate. International Journal of Education, Learning and Development. Vol 5, No 4 pp 66-76, June 2017. 